\title{
Genética Forense. Del laboratorio a los tribunales. Reseña de libro.
}

https://doi.org/10.5377/rcfh.v5i1.8720

\author{
Dr. Manuel Crespillo ${ }^{1}$, Dr. Pedro A. Barrio²
}

1.-Instituto Nacional de Toxicología y Ciencias Forenses, Departamento de Barcelona, Servicio de Biología. C/ La Mercè, 1, 08002, Barcelona, España.

2 Instituto Nacional de Toxicología y Ciencias Forenses, Departamento de Madrid, Servicio de Biología. C/ José Echegaray 4, 28232 Las Rozas de Madrid, Madrid, España.

Como Editora de la Revista de Ciencias Forenses de Honduras, pero sobre todo como profesional del campo de la Genética Forense, me siento honrada de publicar, la reseña de un libro escrito por autores de muy alto nivel profesional y humano, que viene a llenar un enorme vacío, especialmente para los profesionales de la Genética Forense que hablan español. El libro "Genética Forense. Del Laboratorio a los tribunales", resume de manera interesante, el camino recorrido de la disciplina y la contribución que incluso algunos de los autores del libro han realizado para que esta haya llegado hasta donde se encuentra hoy. Al leerlo pensé que la evolución de la Genética Forense de manera figurativa representa el largo camino de regreso a casa, al resarcimiento y la reparación que un análisis de ADN implica para algunas víctimas en ciertos contextos, especialmente los Latinoamericanos.

EI libro está disponible en https://www.amazon.es/GEN\%C3\%89TICA-FORENSE-CRESPILLO-M\%C3\%81RQUEZMANUEL/dp/8490522138

Sin más demora doy paso a los Editores, Manuel C. Crespillo y Pedro A. Barrio

La Genética Forense es una apasionante disciplina científica en constante evolución. Tradicionalmente se la ha considerado como una subespecialidad de la Genética y de la Medicina Legal. Sin embargo, en los últimos años ha adquirido una entidad propia, su evolución va ligada a la revolución tecnológica de las últimas décadas. Hoy en día, se ha consolidado como una herramienta de indudable utilidad en el quehacer diario de los Tribunales de Justicia, dando respuesta a los retos que se plantean desde el ámbito judicial. Desde la introducción de la huella genética en 1985 por Alec Jeffreys, ha habido una evolución continua en el tipo de marcadores y en las tecnologías utilizadas. Sin embargo, como ya ponía de manifiesto el profesor Ángel Carracedo, "los retos prioritarios de la genética forense no son esencialmente tecnológicos: la valoración estadística de la prueba del ADN en los casos complejos (particularmente en mezclas 0 muestras de contacto), la comunicación del valor de la prueba, el control de calidad, el futuro de la I+D, la formación, los estándares éticos, entre otros, son problemas a los que nos tenemos que enfrentar con urgencia" ${ }^{1}$. Pero, además, hay que hacer frente a otros retos que se presentan en una sociedad globalizada, donde los medios de comunicación juegan un papel de gran importancia. De este modo, series de televisión como CSI, NCIS, La Ley y el Orden o Mentes Criminales, que tanto impacto y audiencia tienen, despiertan inquietudes en los televidentes y han conseguido socializar esta disciplina de la ciencia aplicada, hasta el extremo que el receptor de estas series está normalizando conceptos y conocimientos (como ADN, secuenciación, base de datos CODIS, ...), antes restringidos a los especialistas que trabajaban en el ámbito de la Genética Forense. Si añadimos algunos casos mediáticos (como el de OJ Simpson en EEUU, Amanda Knox en Italia, Eva Blanco en España...), se pone de manifiesto la necesidad de una comunicación clara y fluida con distintos interlocutores, no sólo con los colectivos judiciales (magistrados, jueces, fiscales o abogados), sino también con la sociedad en general, ya que algunos países, tendrán su efecto en la comunicación de la pericia. En este marco, ya se están desarrollando 
introducción de los jurados en el marco jurídico de algunas iniciativas, como la de "Sense about Science" cuya guía en inglés destinada al público en general ya se está traduciendo a otros idiomas, entre ellos, al español.

Por otro lado, se ha de tener en cuenta que, de manera mayoritaria, los textos científicos, y entre ellos los relativos a la Genética Forense, se encuentran redactados en inglés ${ }^{3-5}$. Es evidente que, para una mayor difusión de la ciencia, generada en cualquier país, se ha de utilizar aquel idioma más extendido. Independientemente de los artículos científicos publicados en revistas de impacto (como: Forensic Science International: Genetics, Journal of Forensic Sciences, Science \& Justice, Journal of Forensic and Legal Medicine, ...), existen grandes obras de referencia dentro del campo de la Genética Forense, todos ellos publicados en inglés. Sin embargo, cada vez se demandan más textos en español.

Este libro aspira a aportar un pequeño grano de arena al conocimiento de la Genética Forense, y en particular, al conocimiento de la Genética Forense en español. Son escasos los libros de esta área publicados en lengua española, a pesar de disponer de uno de los grupos de trabajo más importantes dentro de la Sociedad Internacional de Genética Forense (International Society for Forensic Genetics -- ISFG), el Grupo de Habla Española y Portuguesa (GHEP-ISFG), que agrupa a más de 150 laboratorios pertenecientes a 23 países de habla española o portuguesa, con excelentes profesionales y una notable productividad científica. Insistimos que, sin ningún tipo de pretensión, con este libro perseguimos, si no llenar un vacío, sí al menos contribuir a llenarlo.

Creemos que este texto es bastante completo, y abarca todos los grandes temas que competen a la Genética Forense. Somos conscientes de la temporalidad del mismo, como hemos indicado, debido a la constante evolución de las tecnologías dentro de la genética forense, y a las próximas revoluciones que se esperan en los próximos 5-10 años. Sólo hay que echar un vistazo a las principales revistas científicas de esta área de conocimiento. No obstante, también creemos que los contenidos de este libro sientan una robusta base conceptual (en español), que podrá servir para futuras (y necesarias) actualizaciones y revisiones.

\section{1.-Presentación y justificación de la estructura y contenido de este libro}

Esta obra se propone abordar la situación actual de la Genética Forense desglosando la temática en tres bloques de contenidos.

El primer bloque incluye tres capítulos, en los que se tratan aspectos generales de la Genética Forense y de los laboratorios que se dedican a este campo, haciendo una revisión de la historia y evolución de la Genética Forense fundamentalmente a través de sus grupos de trabajo y sociedades científicas que reman para la evolución y estandarización de esta disciplina (Capítulo 1). Asimismo, se pondrá de manifiesto la necesidad de establecer un sistema de calidad en los laboratorios de Genética Forense que prestan sus servicios a la Administración de Justicia, y cómo se ha de alcanzar mediante la implantación de la norma ISO/IEC 17025:2017 (Capítulo 2). Este bloque se cierra, analizando uno de los talones de Aquiles de la prueba genética, la contaminación, su trascendencia y su repercusión en el curso de la investigación. Para ello, se incluyen algunos casos de importante repercusión mediática que tratan de ofrecer una perspectiva práctica al lector (Capítulo 3).

En un segundo bloque se incluye un conjunto de 10 capítulos que tratan aspectos más técnicos y metodológicos dentro de la Genética Forense. Se inicia este bloque abordando una fase de gran trascendencia en el análisis genético, como es la recogida de indicios y su remisión a los laboratorios forense, así como de las metodologías aplicadas para la caracterización de fluidos biológicos y otros indicios (Capítulo 4). Se revisan las bases moleculares del proceso de extracción de ADN en los distintos métodos empleados para la recuperación de ADN a partir de las evidencias (Capítulo 5), así como una visión actualizada de los métodos de cuantificación de ADN humano (Capítulo 6). Además, se valoran los marcadores STRs autosómicos de interés forense y las posibles dificultades y retos que plantea su análisis (Capítulo 7). Se analizó una de las principales técnicas que actualmente se aplican para la detección de polimorfismos de ADN, la electroforesis capilar (capítulo 8), ofreciendo una visión práctica de su uso, 
incidencias y posibles soluciones a éstas. Los Capítulos 9 y 10, revisan los llamados marcadores haplotípicos, marcadores del cromosoma $\mathrm{Y}$ y el ADN mitocondrial, de indudable utilidad en genética forense. Pero también se analizaron otros marcadores que poco a poco se están introduciendo en las investigaciones genético forenses, los marcadores fenotípicos (Capítulo 11), y que ayudarán en casos complejos. El Capítulo 12 recoge una completa revisión que aborda el análisis de evidencias o restos de origen no humano (animales, plantas, microorganismos). Y para cerrar este bloque, se hará una completa revisión de las nuevas técnicas de secuenciación masiva (MPS) que se están comenzando a validar y aplicar al campo de la genética forense, tanto para aplicaciones clásicas como en otras nuevas vías de investigación (Capítulo 13).

Finalmente, el tercer bloque de este libro, versa sobre aspectos relacionados con la interpretación de los resultados obtenidos en la prueba genética. Con ello, el primer capítulo de este bloque aborda el estudio genético de las relaciones de parentesco, con el análisis tanto de las paternidades simples como complejas (Capítulo 14). El siguiente, se centra en el tema de los denominados "perfiles de ADN críticos", como son las mezclas o aquellos en los que el ADN está en baja cantidad y/o degradado (Capítulo 15). También se valoran otros casos concretos, como la identificación genética en grandes catástrofes o de personas desaparecidas (Capítulo 16). En el Capítulo 17, se revisará la importancia y la trascendencia de las bases de datos de ADN de interés criminal y su uso para la resolución de casos judiciales con una visión a nivel mundial. La valoración (estadística) de la prueba genética y su presentación ante los tribunales de justicia se desarrolló en el Capítulo 18, abordando aquellos aspectos más relevantes y críticos de esta fase del análisis. El Capítulo 19 desarrolló el formato de los informes periciales en materia de análisis genéticos, exponiendo las características y requerimientos de los mismos, de acuerdo con los requisitos de la norma ISO/IEC 17025:2017, incidiendo en la expresión de resultados y conclusiones, ofreciendo herramientas al lector, mediante la presentación de ejemplos y estrategias de comunicación. Este último bloque cierra con un interesante capítulo sobre los aspectos legales y bioéticos del estudio del ADN con fines de identificación forense (Capítulo 20).

Genética forense. Del laboratorio a los Tribunales, es una obra en la que han participado múltiples autores. Los profesionales que han contribuido a la elaboración de los distintos capítulos de este libro, son expertos de una dilatada experiencia profesional, de contrastada solvencia y reputación internacional, lo cual garantiza la calidad y rigor de esta obra. La obra está concebida para servir de apoyo y consulta a los distintos colectivos que, desde diferentes perspectivas, puedan estar interesados en esta disciplina de las Ciencias Forenses: estudiantes, profesionales del campo científico y del ámbito jurídico, así como miembros de cuerpos y fuerzas de seguridad.

Los editores confían que el futuro lector de este libro, tanto experimentado como aquellos que se inician en la materia, agradezca el tratamiento realizado de todos los temas que lo componen y le resulte de suma utilidad. Para llevar a cabo el abordaje de todos estos contenidos, se ha pretendido dar una visión lo más práctica posible, con un objetivo didáctico. Así, en todos aquellos temas que se presten a ello, se han expuesto casos concretos y reales, para buscar la mejor forma de ilustrar los temas tratados y hacerlos lo más comprensibles posible. Este libro intenta dar respuesta a la necesidad de textos de referencia de calidad en español dentro del campo de la Genética Forense, así como servir de divulgación de esta área de conocimiento.

\section{REFERENCIAS BIBLIOGRAFICAS}

1.-Carracedo A, Salas A, Lareau MV. Problemas y retos de futuro de la genética forense en el siglo XXI. Cuad Med Forense. 2010;16(1-2):31-35.

2.- Sense about Science (GB). Making sense of forensic genetics. [Internet]. London: EUROFORGEN;2017. [consultado 14 de junio de 2018]. Disponible en: http://senseaboutscience.org/wp-

content/uploads/2017/01/making-sense-of-forensicgenetics.pdf

3. Butler JM. Advanced Topics in Forensic DNA Typing. Boston: Academic Press/Elsevier; 2010.

4. Butler JM. Advanced Topics in Forensic DNA Typing: methodology. Burlington: Elsevier Science; 2011.

5. Butler JM. Advanced Topics in Forensic DNA Typing: interpretation. [Internet]. Boston: Elsevier ; 2014. 